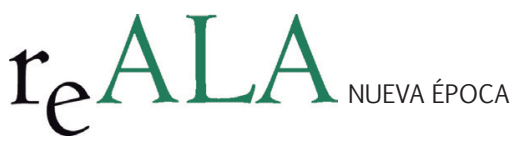

REALA, n 4, julio-diciembre 2015 ISSN: 1989-8975

DOI: http://dx.doi.org/10.24965/reala.voi4.10304

\title{
La cooperación internacional para el desarrollo por los entes locales, tras la reforma operada por la Ley 27/2013
}

\author{
Rafael García Matíes \\ Secretario General del Ayuntamiento de l'Eliana \\ musol@musol.org
}

\section{Resumen}

La modificación de la Ley $7 / 1985$ de 2 de abril Reguladora de las Bases del Régimen Local, por la ley 27/2013, de 27 de diciembre, de racionalización y sostenibilidad de la Administración Local, ha generado una zona de inseguridad jurídica en cuanto a las competencias de los municipios. En el presente artículo se afirma que la competencia en Cooperación Internacional para el Desarrollo de la que los municipios eran titulares antes de la ley 27/2013, sigue siendo competencia municipal. Para ello se parte de la irretroactividad de la reforma por lo que se mantienen las atribuciones otorgadas por leyes anteriores a la misma, como es la Cooperación Internacional para el Desarrollo, de que se trata de una actividad de interés local e incluso de que la Ley del Servicio y la Acción Exterior del Estado dictada con posterioridad ha reforzado esta interpretación.

\section{Palabras clave}

Acción exterior, autonomía, comunidades autónomas, competencias, competencias propias, cooperación, desarrollo, entes locales, municipio, internacional

\section{International cooperation for development by local authorities, after the reform done by Law 27/2013}

\section{Abstract}

The modification of Law 7/1985 of April 2 Regulator of the Bases of Local Regime, by Law 27/2013, of December 27, of rationalization and sustainability of the Local Administration, has generated an area of legal insecurity regarding the competency of the municipality. The present article affirms that the power of International Cooperation for Development of which the municipalities were titled before the law 27/2013, which still is municipal responsibility. For this, it starts with the non-retroactivity of the reform for which they maintain the powers given by the laws before this, such as the International Development Cooperation, which is an activity of local interest and even of the Law of Service and Exterior Action of the State, issued after it has reinforced this interpretation.

\section{Keywords}

Foreign action, autonomy / self-government, autonomous communities, competencies, own competencies, cooperation, development, local entities, municipality, international 


\section{SUMARIO:}

o. Introducción.

1. La Competencia De Las Comunidades Autónomas.

2. La atribución de competencia a los entes locales por la legislación básica.

3. El nuevo marco competencial: la clasificación de las competencias.

4. Las competencias propias municipales.

5. La falta de una disposición transitoria general.

6. La cooperación internacional para el desarrollo y las entidades locales.

7. Las competencias en cooperacion internacional para el desarrollo y la ley 2/2014, de 25 de marzo de la acción y del servicio exterior del estado. Cuestiones puntuales.

7.1 La planificación de la acción exterior, incluida la Cooperación Internacional para el Desarrollo. (Título II de la LASEE).

7.2 Los sujetos de la acción exterior (artículo 5 LASEE).

7.3 Sobre la obligación de mantener informado o comunicar al MAE las actividades de Cooperación por las entidades locales.

7.4 Las entidades que integran la Administración Local estarán sujetas a los instrumentos de planificación de la acción exterior que determinen sus respectivas Comunidades Autónomas.

7.5 Las administraciones locales y las CCAA, tienen facultades para actuar en el exterior y por tanto en la Cooperación Internacional para el Desarrollo.

8. Institucionalizar a la cooperación internacional de los entes locales.

Abreviaturas.

Bibliografia.

\section{INTRODUCCIÓN}

La modificación efectuada por la ley 27/2013, de 27 de diciembre, de racionalización y sostenibilidad de la Administración Local, en adelante LRSAL, ha afectado a la atribución de competencias a las entidades locales. La regulación resultante de la modificación ha venido a introducir dudas acerca de cómo ha afectado a muchas de las competencias hasta ahora ejecutadas por los entes locales.

"Y el resultado, tras un año de aplicación de esta reforma resulta desigual. Pues, por ejemplo, frente a los evidentes avances ... no tan favorable es el balance en cuanto se refiere a las competencias locales, ... lo que conlleva la persistencia de una zona de inseguridad jurídica en este ámbito."

Bello Paredes ${ }^{1}$

A efectuar un análisis sobre cómo afecta a la Cooperación Internacional al Desarrollo, se dirigen estas líneas que como se verá plantean algunas cuestiones sobre las competencias de carácter general.

\section{LA COMPETENCIA DE LAS COMUNIDADES AUTÓNOMAS}

La Constitución Española de 1.978 no contiene en su articulado ninguna referencia explícita a la Cooperación Internacional para el Desarrollo. El fundamento constitucional de la Cooperación, se encuentra para la Ley estatal 23/1988 de 7 de julio de Cooperación Internacional para el desarrollo (en adelante LCID) en el preámbulo de la Constitución Española, en el que la Nación Española proclama su voluntad de colaborar en el fortalecimiento de unas relaciones pacíficas y de eficaz cooperación entre los pueblos de la Tierra.

Igualmente para las Comunidades Autónomas el fundamento está conforme al artículo 20 de la Ley 23/1998 de 7 de julio de Cooperación Internacional para el desarrollo (en adelante LCID) en la solidaridad de las respectivas sociedades con otros pueblos, respetando los principios, los objetivos y las prioridades de la política española definidos por la propia LCID Así como en los principios de coherencia y complementariedad previstos en la normativa de aplicación de la Unión Europea. Y en las últimas modificaciones Estatutarias en algunos casos.

Contrariamente a lo ocurrido respecto a los municipios tal y como se señala más abajo, nada ha modificado la competencia de las Comunidades Autónomas que disponen título jurídico suficiente mediante sus Estatutos de Autonomías (algunas), sus respectivas leyes de Cooperación, además de en el artículo 20 de la LCID. No

1 Bello Paredes 2015a, 1. 
obstante, cabe señalar que las Comunidades Autónomas no son sujetos del derecho internacional. Reiterada doctrina del Tribunal Constitucional (recogida ahora en la Ley de Acción y del Servicio Exterior del Estado) ha declarado (resolviendo conflictos entre el Estado y las Comunidades Autónomas) que toda la acción exterior no puede calificarse de política internacional y por tanto el alcance de "Relaciones Internacionales" atribuida como competencia exclusiva al Estado comprende las materias relativas a la celebración de Tratados (iuscontrahendi), a la representación exterior del Estado ("iuslegationis"), a la creación de obligaciones internacionales y a la responsabilidad internacional del Estado.

"el carácter asimétrico de los efectos alcanzados por la reforma estatal supone mantener vivo el problema local que, desde mi punto de vista, es uno de los problemas irresolutos de la Constitución.”

Bello Paredes 2

La actuación de las Comunidades Autónomas y obviamente también de los entes locales en esta materia no tiene la naturaleza de Tratado, ni obliga al Estado ni lo representa. Se trata de una actuación "expresión de la solidaridad de la sociedad local y autonómica".

\section{LA ATRIBUCIÓN DE COMPETENCIA A LOS ENTES LOCALES POR LA LEGISLACIÓN BÁSICA}

Hasta el 31 de diciembre de 2013 fecha en que entro en vigor la Ley 27/2013 de Racionalización y Sostenibilidad de la Administración Local, (en adelante LRSAL) y salvo un pequeño paréntesis en sus inicios, era pacíficamente admitida la competencia de las entidades locales para actuar en el campo de la cooperación internacional para el desarrollo.

“La carencia competencial derivada del principio de autonomía local,... debe suplirse a través del principio Constitucional de "interés respectivo"

Bello Paredes 3

La ley 7/1985 de 2 de abril Reguladora de las bases del Régimen Local, (en adelante LRBRL), diseñó una atribución competencial general y muy abierta para los municipios. El apartado 1 del artículo 25 establecía que “El Municipio para la gestión de sus intereses y en el ámbito de sus competencias, puede promover toda clase de actividades y prestar cuantos servicios públicos contribuyan a satisfacer las necesidades y aspiraciones de la comunidad vecinal". A las provincias, el artículo 36 les atribuía el fomento y la administración de los intereses peculiares de las provincias. El artículo 2 de la misma ley por su parte se refería a que las leyes debían asegurar a las entidades locales su derecho a participar en cuantos asuntos afecten al círculo de sus intereses. El apartado 2 del artículo 25 enumeraba una serie de materias (no competencias ${ }^{4}$ ) reservadas a los municipios, dentro de las cuales debían ejercer competencias, las cuales debían concretarse "en los términos de la legislación del Estado o de las Comunidades Autónomas”. En este marco tanto el Estado como las Comunidades Autónomas mediante sucesivas leyes, atribuyeron competencias a los entes locales.

Para determinar qué competencias y actividades pueden legalmente asumir los ayuntamientos y cualesquiera otras entidades locales no basta con acudir a la ley básica de régimen local, sino que, fundamentalmente, se debe atender a la legislación estatal y autonómica.

Cositalcr, $2014^{5}$

La Sentencia del Tribunal Constitucional (STC) 214/1989 de 21 de diciembre ${ }^{6}$, señaló que el fin del artículo 2 de la LRBRL era el concretar el alcance de la garantía constitucional de la autonomía local desde la perspectiva de las competencias locales, y que a tal efecto correspondía al legislador estatal la fijación de los principios básicos en orden a las competencias que deba reconocerse a las Entidades Locales estableciendo y garantizando, "su derecho a intervenir en cuantos asuntos afecten directamente al círculo de sus intereses” y que la concreción última de las competencias locales queda remitida a la correspondiente legislación sectorial, ya sea estatal o autonómica, según el sistema constitucional de distribución de competencias entre el Estado y las Comunidades Autónomas. Esta misma sentencia interpretando el párrafo 2 de este articulo 2 de la LRBRL, que establece que "Las Leyes básicas

2 Bello Paredes, $2015^{\mathrm{a}}$, 1.

Bello Paredes 2015b, 2

Tanto antes como ahora lo que atribuye el articulo 25 son materias y no concretas competencias.

Cositalcr 2014, 2.

FJ 3. 
del Estado previstas constitucionalmente deberán determinar las competencias que ellas mismas atribuyan o que, en todo caso, deban corresponder a los entes locales en las materias que regulen", declaró que las leyes básicas deberán establecer qué competencias corresponden en una materia compartida a las Entidades locales, por ser ello necesario para garantizarles su autonomía, sin que ello asegure que la ley básica estatal o la ley sectorial que tal cosa disponga sea, sin más, constitucional, porque si excede de lo necesario para garantizar la institución de la autonomía local, habrá invadido competencias comunitarias, y será por ello, inconstitucional, correspondiendo al propio TC ponderar en cada caso si las competencias atribuidas a los Entes locales son o no necesarias para asegurar su autonomía.

La Ley (sectorial) de Cooperación Internacional para el Desarrollo (LCID), dictada en el marco de las competencias del Estado, determina las competencias que corresponden a las CCAA y a los entes locales, en cooperación internacional para el desarrollo al señalar: “1). La cooperación para el desarrollo que se realice desde las Comunidades Autónomas y las Entidades locales, expresión solidaria de sus respectivas sociedades, se inspira en los principios objetivos y prioridades establecidas en la sección 2.a del capítulo I de la presente Ley. 2). La acción de dichas entidades en la cooperación para el desarrollo se basa en los principios de autonomía presupuestaria y autorresponsabilidad en su desarrollo y ejecución, debiendo respetar las líneas generales y directrices básicas establecidas por el Congreso de los Diputados a que se refiere el artículo 15.1 de la presente Ley y el principio de colaboración entre Administraciones públicas en cuanto al acceso y participación de la información y máximo aprovechamiento de los recursos públicos."

Ya cabe adelantar aquí que la competencia se atribuye por la norma clara y concretamente, no es una atribución genérica de competencias, se dice que se realice, es decir que la norma da por supuesto que los municipios y las CCAA están facultados para realizar esa actividad, no está atribuyendo competencia genéricamente en cooperación, sino que está reconociendo la competencia concreta y específicamente.

“... la cooperación internacional al desarrollo promovida desde las administraciones locales ... no es una actividad administrativa de nueva implantación ni de carácter marginal o secundario. Responde al ejercicio del derecho de cooperación expresado en el artículo 10 de la Carta Europea de Autonomía Local y a la voluntad del legislador constituyente que en la exposición de motivos de la vigente Constitución proclama la voluntad colectiva de "Colaborar al fortalecimiento de unas relaciones pacíficas y de cooperación eficaz entre todos los pueblos de la Tierra."

FONT MONCLUS et alter ${ }^{7}$

Además la LCID en este precepto va más allá de atribuir competencias en la materia:

a) por una parte al decir "Que se realice desde CCAA y Entes locales..." como se ha dicho les está reconociendo y confirmando y por tanto atribuyendo competencias.

b) A la vez lo que hace además es reconocer que los ciudadanos "locales y autonómicos" son solidarios y lo manifiestan y exteriorizan (a través de sus sociedades dice la ley), y, al hacerlo, la ley estatal está reconociendo expresamente que hay un interés relevante de la sociedad local, es decir de los ciudadanos, en la materia. Consecuentemente la ley está reconociendo que la cooperación internacional para el desarrollo es una materia que afecta directamente al círculo de los intereses locales, por lo que de conformidad con el artículo 137 de la Constitución (que declara la autonomía local "Para la gestión de sus intereses") y al artículo 2 de la LRBRL (que señala "Deberá asegurar a los Municipios, las Provincias y las Islas su derecho a intervenir en cuantos asuntos afecten directamente al círculo de sus intereses, atribuyéndoles las competencias que proceda"), les reconoce la competencia, y que aunque no le atribuyera directamente competencias, como hace, debería hacerlo porque existe un interés local en la materia expresamente reconocido en norma con rango de ley Estatal.

La atribución competencial a las CCAA y entidades locales se configura, se norma y se delimita por la remisión que hace el propio artículo 20 de la LCID, a otros preceptos de la ley y a las directrices del Congreso de los Diputados, ahora también al someterla a la reciente Ley de Acción y Servicio Exterior del Estado. No solo se declara y reconoce la competencia sino que, por la remisión a los principios, las directrices del Congreso de Diputados, etc. se configura plenamente y se regula el ejercicio de la competencia en esta materia, sometiéndola a todos esos requerimientos.

No puede el legislador estatal en la modificación de la LRBRL, efectuada por la LRSAL, desconocer:

7 FONT MONCLUS et alter 2014, 19. 
a) El contenido de la autonomía municipal, que aunque como ha declarado el Tribunal Constitucional no es soberanía, sí que supone el derecho a participar en la gestión de sus propios intereses (artículo 137 de la Constitución) y conforme a la Carta Europea de la Autonomía local, es el derecho y la capacidad efectiva de las Entidades locales de ordenar y gestionar una parte importante de los asuntos públicos, en el marco de la Ley, bajo su propia responsabilidad y en beneficio de sus habitantes".

b) Que la competencia sectorial de las Comunidades Autónomas, supone otro límite que el legislador estatal tampoco puede desconocer, en los términos señalados más arriba y

c) Que nada se opone, que las Comunidades Autónomas en el ejercicio de sus competencias puedan atribuir más competencias propias a los municipios de su territorio, aunque no figuren en el listado del artículo 25 de la LRBRL.

"la competencia exclusiva no es sobre un listado cerrado sino solo sobre algunas materias en que las leyes autonómicas y estatales han de atribuir competencias ${ }^{8} . "$

d) Que no toda la legislación básica estatal que afecta a las entidades locales se contiene en la LRBRL. También otras leyes estatales pueden establecer normas básicas que afecten a los entes locales.

e) El contenido de la Carta Europea de la Autonomía Local, ratificada por España.

Hay que tener en cuenta no obstante que:

“La complejidad de nuestra sociedad aconseja aplicar un enfoque de gobernanza a la autonomía local con el fin de integrar de una manera más efectiva a los numerosos y dinámicos agentes públicos, privados y sociales en la actividad pública local. Para lograrlo es necesario poner mayor énfasis en la colaboración y la gestión participada de esos agentes y que los poderes públicos asuman que ya no es posible satisfacer las necesidades de los ciudadanos sin contar con ellos."

ARENILLA SAEZ, MANUEL ${ }^{9}$

La configuración conjunta de esas normas ( art 25 y 7.2 LRBRL) con el art. 4.2 de la Carta Europea de Autonomía Local, nos lleva a afirmar que siguen estando vigentes las normas con rango de ley, estatales y autonómicas, que contengan competencias municipales en materias distintas a las recogidas en este artículo, lo que también es clave para entender el auténtico alcance de la LRSAL.

Cositalcr $2014^{10}$

\section{EL NUEVO MARCO COMPETENCIAL: LA CLASIFICACIÓN DE LAS COMPETENCIAS}

El nuevo artículo 7 de la LRBRL en la redacción que le da la LRSAL, clasifica las competencias locales en propias, delegadas y en otras diferentes de unas y otras, que no denomina. Las propias son las que mediante norma con rango de ley se atribuyan; las delegadas, las que le deleguen, es decir son competencias de otros que ejercerán en su nombre y bajo la dirección del delegante. Finalmente, esa otra tercera categoría para cuyo ejercicio se precisará de dos informes vinculantes: a) uno económico que acredite que no se pone en riesgo la hacienda local y b) otro donde se señale la inexistencia de duplicidades y aunque esta tercera categoría no son competencias delegadas, también deberán ejercerse (realizarse dice la ley), en los términos previstos en la legislación del Estado y de las Comunidades Locales.

En realidad no hay tres categorías sino dos. Las competencias propias y las que no son propias porque son de otros sujetos, pudiendo ejercerse estas últimas por delegación en sentido estricto o bien por una delegación que podríamos denominar inversa, es decir no se delega por el titular sino que se solicita por quien quiere ejercerla, que además si se le acepta, al contrario de lo que ocurriría con la delegación en sentido estricto es quién asume el coste. Es una delegación rogada, a la que se accede si quién la solicita dispone de capacidades y recursos, porque lo de la duplicidad es en muchos casos difícil de acreditar.

El artículo 7 en relación con el art. 25 de la LRBRL restringe al menos formalmente, lo que hasta ahora hemos entendido como autonomía local.

8 JORDI CASES, 2014, 105.

9 ARENILLA SAEZ, 2015, 7.

10 COSITALCR 2014, 3. 
Las competencias propias, pese a que se afirma que se ejercen en régimen de autonomía y bajo la propia responsabilidad, se dice también que en este ejercicio es necesario atenderse siempre a la debida coordinación en su programación y ejecución con las demás Administraciones Públicas.

Las competencias delegadas, siguen el régimen de las delegaciones, el delegante determinará como se ejercen y además preverán técnicas de dirección y control de oportunidad y eficiencia. Se afirma que la delegación deberá ir acompañada de la correspondiente financiación. Aunque no se dice de suficiente, sino correspondiente y además que no podrá suponer mayor gasto para las administraciones. La ley es cierto prevé firmes garantías para el ente local en cuanto al pago de los compromisos por el delegante.

Finalmente las otras competencias distintas de las dos anteriores, dejan poco margen a la autonomía, porque se las somete, al requisito de disponer de recursos, a no comprometer la sostenibilidad financiera del resto de la hacienda municipal y finalmente a que se emitan informes (vinculantes), por la administración competente por razón de la materia en el que se señale la inexistencia de duplicidades y de la que ejerza la tutela financiera sobre la sostenibilidad financiera.

Es cierto que en el marco anterior a la LRSAL había también competencias propias, y otras a las que se les denominó impropias y también se producían delegaciones y que las leyes del Estado y de las Comunidades Autónomas distribuían y regulaban competencias locales, pero el marco de actuación para los entes locales era mucho más amplio y el respeto a la autonomía local mucho más claro. Algunos excesos en asumir competencias sin recursos, que ciertamente se llevaron a cabo por algunos entes locales puntualmente, creo que no debieron dar lugar a esta regulación, sin duda más restrictiva. Ahora, en la nueva regulación todas las competencias están profundamente "participadas” por las Comunidades Autónomas y el Estado.

Los excesos debieron resolverse con controles, singularmente judiciales y sólo respecto a los contraventores.

\section{LAS COMPETENCIAS PROPIAS MUNICIPALES}

La redacción actual del artículo 25.1, dice ahora que “1. El Municipio para la gestión de sus intereses y en el ámbito de sus competencias, puede promover actividades y prestar los servicios públicos que contribuyan a satisfacer las necesidades y aspiraciones de la comunidad vecinal en los términos previstos en este artículo"

La anterior redacción no incluía el párrafo: "En los términos previstos en el artículo”, por lo que si existía interés municipal y ello contribuía a satisfacer alguna necesidad o aspiración de la comunidad, unido a la fórmula general contenida en el artículo 2 de la LRBRL el municipio podía considerar que tenía competencias sobre una concreta materia, porque no era difícil fundar la existencia de competencia en alguna de las que enumeraba el artículo 25.2 de la LRBRL e incluso en algunas que no figuraban.

Se decía que solo la Ley determinaba las concretas competencias en las materias del apartado 2, pero ya la ley 7/1985 en ese primer párrafo estaba reconociendo o atribuyendo competencias, genéricamente pero competencias.

Ahora en la nueva redacción, los términos de configuración de esas competencias propias serán las que se atribuyan de entre las materias del apartado 2 y además se sometan a los requisitos que se contienen en los apartados 3, 4 y 5 siguientes del precepto que señalan:

“3. Las competencias municipales en las materias enunciadas en este artículo se determinarán por Ley debiendo evaluar la conveniencia de la implantación de servicios locales conforme a los principios de descentralización, eficiencia, estabilidad y sostenibilidad financiera.

4. La Ley a que se refiere el apartado anterior deberá ir acompañada de una memoria económica que refleje el impacto sobre los recursos financieros de las Administraciones Públicas afectadas y el cumplimiento de los principios de estabilidad, sostenibilidad financiera y eficiencia del servicio o la actividad. La Ley debe prever la dotación de los recursos necesarios para asegurar la suficiencia financiera de las Entidades Locales sin que ello pueda conllevar, en ningún caso, un mayor gasto de las Administraciones Públicas. Los proyectos de leyes estatales se acompañarán de un informe del Ministerio de Hacienda y Administraciones Públicas en el que se acrediten los criterios antes señalados.

5. La Ley determinará la competencia municipal propia de que se trate, garantizando que no se produce una atribución simultánea de la misma competencia a otra Administración Pública”.

Por tanto, a partir de ahora, las competencias propias “en las materias enunciadas” las determinarán las normas con rango de ley material (autonómicas o estatales), las cuales deben valorar si es conveniente o no la implantación de servicios locales en atención a los principios que enumera, deberán valorar el impacto económico sobre las Administraciones afectadas, y deberán prever los recursos necesarios para asegurar la suficiencia financiera. 


\begin{abstract}
“No hay que olvidar que las Comunidades Autónomas pueden “elevar" en su territorio los estándares estatales de autonomía local. De hecho, varias de ellas incluyen en su legislación de régimen local títulos competenciales generales o competencias complementarias similares a las del articulo 28 de la LRBRL derogado."
\end{abstract}

\title{
SALAZAR BENITEZ, OCTAVIO ${ }^{1}$
}

Nótese que el artículo 25.2 no atribuye competencias, sino que dice que en esas materias se atribuirán competencias y que las competencias que se atribuyan en esas materias serán propias. O dicho de otro modo, las materias enumeradas no facultan a los municipios por si sólo para intervenir en esas materias, deberá ser una ley autonómica o estatal la que atribuya la concreta competencia sobre cada materia, dentro del marco de esta ley, tal y como se ha señalado por la STC citada 214/1989. Además tampoco dice este precepto que las únicas competencias propias serán las que enumera.

“Tras una cierta desorientación inicial, en estos momentos (a pesar del Consejo de Estado y de la opinión de un sector minoritario de la doctrina) puede concluirse que las competencias municipales son aquellas atribuidas expresamente por el legislador sectorial estatal o autonómico, según el sistema interno de distribución de competencias entre el estatal o autonómico, según el sistema interno de distribución de competencias entre el Estado y Comunidades Autónomas. Esta tesis, no sin resistencias iníciales, se ha terminado por imponer en el propio Ministerio de Hacienda y Administraciones Públicas."

\section{Jiménez Asensio ${ }^{12}$}

\section{LA FALTA DE UNA DISPOSICIÓN TRANSITORIA GENERAL}

A la entrada en vigor de la LRBRL en 1.985, los entes locales venían ejerciendo sus competencias en el marco de la legislación vigente que en muchos casos era la preconstitucional. Para conectar entonces la vieja con la nueva legislación y dar tiempo para la transición entre las anteriores normas y las que había que dictar conforme al apartado 25.2 de la Ley 7/1985, la disposición transitoria segunda estableció “Hasta tanto la legislación del Estado y la de las Comunidades Autónomas que se dicte de conformidad con lo establecido en los artículos.... 25, apartado 2 y 36 de esta Ley, no disponga otra cosa, los Municipios, Las Provincias y las Islas conservarán las competencias que les atribuye la legislación sectorial vigente en la fecha de entrada en vigor de esta Ley. Los Municipios ostentarán, además, en las materias a que se refiere el artículo 28 de esta Ley, cuantas competencias de ejecución no se encuentren conferidas por dicha legislación sectorial a otras Administraciones públicas". El artículo 28 (suprimido ahora por la LRSAL) facultaba a los municipios para realizar actividades complementarias de las propias de otras administraciones públicas.

La modificación mediante la LRSAL de la LRBRL sin embargo, no ha previsto el régimen transitorio general de la aplicación de las modificaciones que introduce que hubiera sido necesario, singularmente en este campo de las competencias, lo que no impidió que la norma entrara en vigor el día siguiente al de su publicación en el Boletín Oficial del Estado. Es cierto que si hay disposiciones transitorias pero solo respecto a algunas materias.

“Los problemas... Parten especialmente de la inexistencia de un sistema o régimen transitorio de competencias municipales o de adaptación al sistema anterior a los presupuestos del nuevo. La LRSAL, queriendo o sin querer, ha establecido un antes y un después del régimen de competencias municipales, pero con dos mundos o ámbitos sin conexiones aparentes..."

\section{Jiménez Asensio ${ }^{13}$}

No es posible considerar que está vigente la disposición transitoria de la ley 7/1985, porque aquella hay que entenderla referida a las situaciones que modificaba la propia LRBRL en 1985, lo cual viene reforzado porque en aquellos aspectos que el legislador ha querido regular la transitoriedad lo ha hecho (salud, educación y servicios sociales entre otras).

\footnotetext{
11 SALAZAR BENITEZ, OCTAVIO 2015.

12 JIMENEZ ASENSIO, 2014.

13 JIMENEZ ASENSIO, 2014.
} 
Conforme al artículo 2.2 del código civil “2. Las leyes sólo se derogan por otras posteriores. La derogación tendrá el alcance que expresamente se disponga y se extenderá siempre a todo aquello que en la ley nueva, sobre la misma materia, sea incompatible con la anterior. Por la simple derogación de una ley no recobran vigencia las que ésta hubiere derogado.

La disposición derogatoria de la Ley 27/2013 establece "A la entrada en vigor de esta Ley quedan derogadas cuantas disposiciones de igual o inferior rango se opongan a o contradigan lo en ella establecido".

Con esta disposición derogatoria alguien podría entender, respecto a las competencias, que todas las normas que se refieran a materias o actividades no previstas en la propia ley tal y como resulta de la modificación operada por la LRSAL, habrían quedado sin efecto, y en este sentido como, entre otras, la Cooperación Internacional para el Desarrollo no figura en el listado del articulo 25.2 actual como propia municipal, solo podría ser ejercida o como delegada o como distinta de las delegadas o propias y para su ejercicio se precisarían de las autorizaciones a que se refiere el artículo 7.4. Esta norma habría derogado no sólo la anterior regulación contenida en la LRBRL, sino también toda la contenida en la legislación sectorial autonómica y estatal que no encontrara su reconocimiento en la modificación de la LRBRL, lo que incluiría no sólo a las materias excluidas ahora del apartado 2 del artículo 25 de la LRSAL, sino a todas las leyes sectoriales autonómicas y estatales que no se dictaran conforme a los requisitos 3. 4 y 5 del artículo 25 citado. Es decir la práctica totalidad de las competencias que actualmente desempeñan las entidades locales, porque estos últimos apartados introducen exigencias que antes no estaban vigentes.

Si admitiéramos esta interpretación, como se ha dicho, ello no solo afectaría a las competencias en Cooperación internacional para el Desarrollo, sino a muchas otras competencias ahora desarrolladas o ejercidas por las entidades locales que les fueron atribuidas, en el marco de la legislación anterior a la modificación de la LRSAL mediante normas con rango de ley dictadas por el propio Estado y por las Comunidades Autónomas en el ámbito de sus competencias y además afectaría a materias de la competencia de las Comunidades Autónomas asumidas en sus propios estatutos de autonomía y que por el principio de la competencia son indisponibles para el legislador Estatal ordinario.

La inexistencia de una disposición transitoria general en la LRSAL para la aplicación de la norma, que hubiera sido deseable en términos análogos a los de la que se dictó en 1985, unido al alcance de la disposición derogatoria, hacen necesario:

En primer lugar es importante señalar que el artículo 25 de la LRBRL no dice que las únicas competencias que serán propias de los municipios serán las que figuran en el apartado 2, sino que en todo caso las que se atribuyan en esas materias serán competencias propias..." Por tanto no niega que haya, ni tampoco que pueda haber, más competencias que se ejerzan como propias, sino que en estas materias se ejercerán competencias y que las que se atribuyan en el futuro de las del listado serán también propias y deberán someterse ahora a más requisitos para que garanticen la sostenibilidad y la estabilidad financiera (los apartados 3 y siguientes).

“El primero de los puntos a determinar en este nuevo mapa de competencias municipales es si el catálogo de materias recogido en el artículo 25.2 de la LRBRL, es de naturaleza abierta o cerrada. Ese término... De "en todo caso" parecería indicarnos que no se trataría de una relación cerrada y la remisión a la legislación autonómica también parecería decirnos que, a través de esta vía, podría ampliarse dicho catalogo."

\section{De Diego Gómez ${ }^{14}$}

La ley entró en vigor a todos los efectos incluido el de las competencias el día 31 de diciembre de 2013 y es aplicable desde esa fecha y no antes. El principio Constitucional de irretroactividad de las normas no favorables impide su retroactividad (en este caso no es difícil admitir que deben entenderse no favorables aquellas disposiciones de la ley que limiten la autonomía municipal para la gestión de sus intereses declarado en el artículo 137 de la Constitución). Por tanto la nueva regulación, solo es aplicable respecto a las leyes sobre las materias enumeradas en el artículo 25.2 de la LRBRL modificado que se dicten con posterioridad a su vigencia, y correlativamente que subsistirán las normas contenidas en las leyes del Estado o de las Comunidades Autónomas dictadas con anterioridad a su vigencia en el marco de sus respectivas competencias, estuvieran o no en el listado. Todo ello sin perjuicio de que el Estado o las Comunidades Autónomas puedan por una parte eliminar totalmente competencias que no figuran ya en el listado del articulo 25.2 LRBRL, o regular de modo diferente las que continúan en el listado. Pero la modificación operada por la LRSAL no es retroactiva.

14 DE DIEGO GOMEZ, ALEJANDRO, 2014. 
A la entrada en vigor de la LRSAL los municipios ejercían:

a) Competencias atribuidas por leyes sectoriales del Estado y de las Comunidades autónomas de las materias incluidas en el listado del artículo 25. 2. de la LRBRL.

b) Competencias atribuidas por leyes sectoriales del Estado y de las Comunidades Autónomas de materias no incluidas en el listado del artículo 25.2. de la LRBRL.

c) Competencias asignadas por normas de rango inferior a la ley atribuidas por el Estado o las Comunidades Autónomas, estuvieran o no dentro del listado.

d) Actividades no atribuidas por norma Estatal o Autonómica alguna.

e) Actividades complementarias de las de otras Administraciones al amparo del artículo 28.

Con respecto a dichos grupos de competencias:

- La LRSAL no ha afectado a las competencias a que se refirieren los apartados a) y b) anteriores. En el caso del apartado b) porque la cláusula del artículo 25.2 de la LRBRL es abierta. “En todo caso" en esas materias, pero no excluye otras. Basta que sea "en los términos "de la legislación del Estado o de las Comunidades Autónomas. Es decir norma con rango de ley.

- En el caso del apartado c) las competencias que se hayan atribuido por norma con rango inferior a la ley de las del listado del art. 25.2, deben considerarse inválidas, por contrarias al principio de legalidad exigido tanto antes como ahora por el artículo 25. Aunque aquí podríamos encontrarnos con algunas singularidades, como por ejemplo las que se ejercen atribuidas por acuerdos o convenios. O por normas reglamentarias en desarrollo de leyes formales que si atribuyen las competencias.

- En cuanto a los apartados d) y e), en esos casos se habla de realizar actividades y prestar servicios públicos y no de ejercer competencias. Esta diferencia es importante. Las competencias facultan para realizar actividades y prestar servicios, pero no al revés. En el caso del apartado d) el artículo 25.1 de la LRBRL en Su anterior redacción se configuraba como una norma básica estatal que atribuía directamente la posibilidad de realizar actividades a los municipios. Esta norma ahora desaparece por lo que si le afecta la disposición derogatoria hacia el futuro pero existen cuanto menos dudas respecto a las actuaciones que se realizan a su amparo y que fueron reguladas por el propio municipio con anterioridad a la LRSAL y están vigentes. Estimamos que las que han sido asumidas reglamentariamente a través de ordenanza por el propio municipio en todo caso subsistirían y respecto al resto deberían examinarse una a una.. El artículo 25.1 LRBRL en su anterior redacción era una norma que facultaba al municipio para realizar actividades. Si se realizaban sin más, es posible entender que esas actividades ya no encuentran cobertura jurídica si no figuran en el listado del artículo 25, pero si al amparo del precepto se estableció una ordenanza, esta jugaría aquí un papel semejante al de la ley necesaria para atribuir competencias por las CCAA y el Estado y no sería difícil entender que están vigentes.

- En el caso del apartado e) no hay duda alguna, lo que se disponía en el artículo 28 era la posibilidad de realizar actividades complementarias, y por tanto la derogación elimina esa facultad a los municipios. Ya no hay título jurídico para realizar esas actividades complementarias actualmente más que por la vía de la delegación o del artículo 7.4. En cualquier caso, será necesario examinar una a una las actividades y comprobar cuantas de las actividades del apartado d) no pueden considerarse incluidas a la vez en el apartado e) o en normas autonómicas.

La disposición derogatoria de la LRSAL hay que interpretarla en el sentido de que quedan derogadas las disposiciones que se opongan a o contradigan lo en ella establecido conforme a lo señalado ${ }^{15}$.

Singularmente deben considerarse derogadas aquellas normas en que la propia LRSAL concrete o excluya una competencia. Aunque con una técnica defectuosa, así debe ser considerado el listado de las competencias que se pueden delegar del artículo 28, porque sin son delegables es que no son ya locales, sin perjuicio de que pudiera tratarse en algún caso de competencias autonómicas indisponibles por el legislador ordinario estatal que estaría aquí invadiendo competencias de las Comunidades Autónomas, aunque pronunciarse sobre esto no sea objeto de esta reflexión.

Aquellas competencias que se atribuyeron por leyes estatales o autonómicas a los entes locales al amparo de las materias que figuraban expresamente en la anterior redacción del artículo 25.2 y que también figuran

15 Conforme al artículo 2.3 del Código Civil. Las leyes no tendrán efecto retroactivo si no dispusieren lo contrario, por lo que no pueden retrotraer sus efectos, salvo que así se disponga expresamente. 
ahora deben considerarse como propias municipales, incluidas aquellas competencias que se otorgaron en virtud de "la materia" contenida en el genérico apartado 1 del artículo 25 contenidas en una disposición (reglamento $\mathrm{u}$ ordenanza) local ${ }^{16} \mathrm{y}$ con el mismo motivo aquellas otras materias que se atribuyeron o reconocieron por leyes sectoriales sobre cualquier materia, aunque no estuvieran en el listado de materias del artículo 25.2, como es el caso de las atribuidas por la Ley de Cooperación Internacional para el Desarrollo entre otras muchas.

El nuevo listado de materias del actual artículo 25.2 LRBRL ha eliminado algunas de las contenidas en la anterior redacción y añadido otras.

a) Sobre las que elimina, esa sola desaparición no supone que queden sin efecto las atribuciones efectuadas por normas con rango de ley por el Estado o las Comunidades Autónomas, sino que se ha eliminado su carácter básico de garantía de la autonomía municipal respecto esa materia. La legislación sectorial que atribuyó las competencias sigue estando vigente, si bien, ahora el legislador autonómico o estatal puede derogar las competencias otorgadas al haberse eliminado la exigencia que se le atribuyan competencias en esas materias.

b) Respecto a las materias que añade la nueva ley, y también respecto a las anteriores que se desarrollen a partir de su entrada en vigor, ahí es aplicable plenamente la nueva regulación. El legislador sectorial deberá atribuir competencias en esas materias y además hacerlo con la observancia de todos los requisitos del artículo 25.

Hay que tener en cuenta que las leyes tanto las de régimen local, como las sectoriales de las Comunidades Autónomas han atribuido durante la vigencia de la LRBRL, muchas competencias a las entidades locales y lo han hecho en el marco de las competencias reconocidas por sus Estatutos de Autonomía y que por tanto estas competencias subsisten en la actualidad, pese al tenor de la adicional tercera de la LRSAL que señala que la regulación es aplicable a todas las Comunidades Autónomas, porque lo será o no en la medida en que respete la distribución competencial entre el Estado y las Comunidades Autónomas.

Como se ha señalado una cosa son las materias del artículo 25.2 y otra las competencias. Lo que se dice, consecuentemente con el artículo 2 de la LRBRL, que garantiza el derecho a intervenir en los asuntos que les afectan, es que en todas esas materias los municipios deberán ejercer competencias, y estás tendrán la naturaleza de propias. Pero las concretas competencias que deberán ejercer de las relacionadas serán aquellas que una norma con rango de ley les atribuya, siempre que se dicten en el marco de sus competencias por el Estado o por las Comunidades Autónomas.

Si interpretáramos la disposición derogatoria literalmente, deberíamos efectuar una revisión de todas las competencias atribuidas a las entidades locales, y considerar derogadas a) todas las atribuidas en el marco de las materias que, aun estando en el listado del anterior y del actual artículo 25.2 de la LRBRL no se hayan dictado con los requisitos de los apartados 2, 3 y 4 de la redacción actual y b) y también todas aquellas que no figuraban en el listado anterior ni en el actual, y se asignaron sin las previsiones relativas a los recursos y/o autorizaciones necesarios. Ello no es así.

\section{Del tenor literal de la disposición derogatoria resulta que:}

Los apartados 3, 4 y 5 del artículo 25, se refieren al futuro, es decir a que las competencias que dentro de esas materias se atribuyan después de su entrada en vigor lo serán solo por ley y deberán contener las previsiones sobre la conveniencia, y acompañadas de la memoria económica, y la garantía de que no se produce una atribución simultánea. Por tanto no se está refiriendo a las situaciones nacidas con anterioridad que subsisten. Claramente subsisten todas aquellas que se referían a materias que también estaban relacionadas en el artículo 25.2 de la LRBRL anterior a la modificación. Así todas las atribuciones efectuadas por Leyes del Estado y de las Comunidades Autónomas respecto a materias del listado del artículo 25.2, tanto en su redacción anterior, como en la actual entiendo no hay duda que subsisten actualmente porque no han sido modificadas.

16 Las competencias atribuidas mediante norma con rango de ley por el Estado o la CCAA atribuyendo competencias en materias del anterior artículo 25.2 están vigentes conforme a lo razonado más arriba. El artículo 25.1 atribuía directamente al municipio la capacidad de identificar y asumir actividades cuando este considerara que concurrían las circunstancias señaladas, las cuales derivan directamente del artículo 2 de la LRBRL. Así pues cuando se trataba solo de la realización de actividades singulares, al amparo del actual articulo 25.1 la nueva regulación impide continuar realizándolas porque ha sido derogado, pero cuando este desarrollo se incluyó en una ordenanza aprobada durante la vigencia del anterior artículo 25.1, se le ha dado un valor equivalente al que tiene la ley autonómica o estatal atribuyendo competencias en las materias que figuraban en la anterior relación del artículo 25.2 de la LRBRL o incluso en otras que no figuraban. Por tanto y sin perjuicio de que hay que examinar cada materia concreta estimamos que es posible efectuar esta interpretación, que no se extendería por ejemplo a la realización de actividades complementarias, cuyo título jurídico sería no el 25.1 sino el 28 de la anterior LRBRL. 
Igualmente, las competencias que se atribuyeron con normas con rango de ley fundadas en el artículo 25.1 en la redacción anterior, subsisten también. Lo mismo puede decirse respecto a las asumidas por los propios municipios en normas reglamentarias al amparo del artículo 25.1 y respecto a las restantes asumidas por los municipios sin norma habilitante alguna la cuestión es más compleja. En principio no, aunque la inexistencia de transitoriedad hace que deba examinarse la cuestión con cuidado.

Respecto a las materias y competencias o actividades que han resultado afectadas por la modificación introducida por la LRSAL, esta entró en vigor ya, inmediatamente, pero necesariamente debe producirse una transitoriedad de facto. Hay previsiones presupuestarias y también personal y medios en funcionamiento y previsiones que, como en el caso de la coordinación de los servicios del artículo 26 por las Diputaciones, en tanto no se establezcan las normas coordinadoras y se adopten las oportunas medidas deben continuar atendiéndose conforme la interpretación expuesta más arriba.

Las competencias que expresamente enumera ya el artículo 27, como que pueden delegarse, suponen que el legislador no las considera ya competencias municipales, así resulta al decir que podrán ser delegadas, pero mientras no se delegan ni asumen por la Comunidad Autónomas o el Estado, de facto hay que continuar prestándolas. Todo ello sin perjuicio de que alguna de las competencias que se declaran como delegables, puedan en realidad ser competencias indisponibles para el legislador estatal, al tratarse de competencias sectoriales atribuidas por los Estatutos de Autonomía, extremo cuya declaración corresponde al Tribunal Constitucional.

“La aplicación 'retroactiva' de las previsiones del artículo 7.4 a situaciones preexistentes plantea objeciones formales y materiales o estrictamente jurídicas, frente a otras que se pueden encuadrar en el plano de la razonabilidad y de la eficiencia."

Martin Pérez ${ }^{17}$

\section{LA COOPERACIÓN INTERNACIONAL PARA EL DESARROLLO Y LAS ENTIDADES LOCALES}

La Ley 23/1988 de Cooperación Internacional para el Desarrollo, vigente actualmente establece en su artículo 20:

“1. La cooperación para el desarrollo que se realice desde las Comunidades Autónomas y las Entidades locales, expresión solidaria de sus respectivas sociedades, se inspira en los principios objetivos y prioridades establecidas en la sección 2. a del capítulo I de la presente Ley.

2. La acción de dichas entidades en la cooperación para el desarrollo se basa en los principios de autonomía presupuestaria y autorresponsabilidad en su desarrollo y ejecución, debiendo respetar las líneas generales y directrices básicas establecidas por el Congreso de los Diputados a que se refiere el artículo 15.1 de la presente Ley y el principio de colaboración entre Administraciones públicas en cuanto al acceso y participación de la información y máximo aprovechamiento de los recursos públicos".

Igualmente las Leyes de Cooperación Internacional para el desarrollo, dictadas por las Comunidades Autónomas reconocen a los entes locales como actores de la Cooperación Internacional para el Desarrollo.

La competencia de Cooperación Internacional para el Desarrollo al no estar incluida en el listado de materias del artículo 25.2 de la LRBRL algunos la han considerado, del tercer grupo del artículo 7, es decir distinta a las propias o delegadas. Para las de este grupo se establece en el apartado 4 del citado precepto que:

“4. Las Entidades Locales solo podrán ejercer competencias distintas de las propias y de las atribuidas por delegación cuando no se ponga en riesgo la sostenibilidad financiera del conjunto de la Hacienda municipal, de acuerdo con los requerimientos de la legislación de estabilidad presupuestaria y sostenibilidad financiera y no se incurra en un supuesto de ejecución simultánea del mismo servicio público con otra Administración Pública. A estos efectos, serán necesarios y vinculantes los informes previos de la Administración competente por razón de materia, en el que se señale la inexistencia de duplicidades, y de la Administración que tenga atribuida la tutela financiera sobre la sostenibilidad financiera de las nuevas competencias.

En todo caso, el ejercicio de estas competencias deberá realizarse en los términos previstos en la legislación del Estado y de las Comunidades Autónomas".

Si se tratara de una competencia que se comenzara a desempeñar ahora por los entes locales, y no se hubiera dictado la LCID ni ninguna ley por la Comunidad Autónoma, efectivamente, estaríamos en el supuesto de este apartado y serían necesarios esos informes vinculantes previos al ejercicio.

17 MARTIN PEREZ, 2014 
“... la cooperación internacional al desarrollo promovido desde las administraciones locales no es una actividad administrativa de nueva implantación ni de carácter marginal o secundario. Responde al ejercicio del derecho de cooperación expresado en el artículo 10 de la Carta Europea de Autonomía Local y a la voluntad del legislador constituyente que en la exposición de motivos de la vigente Constitución proclama la voluntad colectiva de "Colaborar al fortalecimiento de unas relaciones pacíficas y de cooperación eficaz entre todos los pueblos de la Tierra."

\section{FONT MONCLUS ${ }^{18}$}

No obstante, la Cooperación Internacional para el desarrollo es una competencia atribuida con anterioridad a los entes locales, mediante ley formal y antes ya fue asumida por los entes locales, al amparo del anterior artículo 25.1 de la LRBRL y normas autonómicas, además de que como hemos visto la regulación introducida por la LRSAL no se refiere a las situaciones que nacieron al amparo de la anterior normativa. Por ello la competencia en Cooperación ha sido otorgada por una ley sectorial, ha nacido con anterioridad y está vigente en estos momentos respecto a los municipios y demás entes locales.

No se trata de una competencia atribuida por una norma básica al no figurar la materia en el artículo 25.2 anterior ni en el actual de la LRBRL ni una competencia obligatoria, incluida en el artículo 26 de la LRBRL, por lo que podrá o no prestarse por el ente local, y es una competencia disponible para el legislador Estatal, salvo en los supuestos en que alguna Comunidad Autónoma la ha incluido como competencia en sus Estatutos. Es una competencia voluntaria (ejercida bajo su responsabilidad dice la LCID) y obviamente habrá de someterse a la ley de Sostenibilidad y Estabilidad presupuestaria. Pero en estos momentos es una competencia local, porque la redacción del artículo 25.2 de la LRBRL dice que ejercerán, en todo caso como competencias propia las que enumera. No dice que se ejercerán exclusivamente esas como competencias propias, ni tampoco que solo esas competencias sean propias sino que tal y como se ha dicho más arriba, esas las ejercerá como propias, pero puede haber otras que se ejerzan también como propias, también anterior a la modificación. La CID es una competencia propia.

La Cooperación Internacional para el Desarrollo es una competencia que el legislador estatal en la LCID, como se ha señalado, lo que hace es reconocer la incardinación de la competencia en Cooperación Internacional para el Desarrollo tanto de las CCAA como de los entes locales, en la expresión solidaria de sus sociedades, y al hacerlo, reconoce expresamente el interés local, en esa materia y eso sí, señala que su ejercicio se efectuará bajo su responsabilidad añadiendo otros requisitos para ello, y por tanto le atribuye la competencia y le reconoce el derecho a intervenir en esa materia lo hace expresamente y además establece una regulación de este ejercicio.

Alguna interpretación consideró que si un Ayuntamiento con anterioridad a la entrada en vigor de la LRSAL viniera ejerciendo competencias distintas de las que la LRSAL enumera como materias propias o delegadas y deseara seguir haciéndolo, debería promover el oportuno expediente al amparo del artículo 7.4 de la LRBRL para justificar que el ejercicio de esas competencias no pone en riesgo la sostenibilidad financiera del conjunto de la Hacienda municipal y que no se incurre en un supuesto de ejecución simultánea del mismo servicio público con otra Administración Pública. De aceptarse esto, ello afectaría a la CID.

Como se ha puesto ya de manifiesto, discrepo de esa interpretación, por las razones ya expuestas más arriba. Lo que hace esa interpretación no es aplicar la norma a partir de su vigencia sino que la aplica retroactivamente, porque se pretende aplicar a una actividad que se está realizando, al amparo de una ley vigente dictada anteriormente y que no ha sido derogada. Podría admitirse esta retroactividad respecto a actividades o servicios que se estuvieran prestando, sin título jurídico alguno o aunque tuvieran título este no estuviera contenido en una norma estatal o autonómica con rango de ley, pero no así en el caso de que haya una ley que haya atribuido esa competencia, como es el caso de la Cooperación Internacional para el Desarrollo que además de fundamentarse en la genérica atribución competencial del anterior artículo 25.1 lo hacen en normas estatales y autonómicas vigentes e incluso en pronunciamientos de organismos internacionales.

"No podemos obviar referirnos a un buen número de pronunciamientos internacionales entre los cuales se destaca la importancia y el creciente rol de los municipios en el trabajo por la cooperación, la paz y los derechos humanos. Entre otros, la Conferencia de Florencia sobre Ciudad y Cooperación para el desarrollo (1983); 1a Conferencia Europea de Colonia sobre Ciudades y Desarrollo (1985) que hacía '...una llamada a las autoridades locales para que apoyen y estimulen los intercambios de cooperación Norte/ Sur, junto con las ONG', considerando este proceso de descentralización

18 FONT MONCLUS et alter, 2014, 19. 
como un punto de partida —y reto - para incrementar la sensibilización de la opinión pública hacia una mayor comprensión de los problemas Norte/ Sur; la Carta de Berlín (1992) y su Plan de Acción, recogido en el documento "Iniciativas Locales para el Desarrollo Sostenible."

FONT MONCLUS et alter ${ }^{19}$

El artículo 25.2 de la LRBRL en la redacción dada por la LRSAL, lo que hace es relacionar las "materias" en que podrán atribuirse competencias a los municipios, no atribuye el las competencias, sino que señala el cauce y el contenido para otorgarlas, por eso no cabe entender que ese precepto está derogando normas vigentes que sí otorgan competencias y además lo hicieron conforme al ordenamiento jurídico vigente cuando se dictaron.

Por todo ello se estima que las entidades locales mantienen la competencia actual en materia de cooperación internacional para el desarrollo, reconocida por la LCID y por las leyes de las Comunidades Autónomas, debiendo obviamente someterse en su ejercicio a la normativa actual, es decir a la LCID estatal, a la de la correspondiente Comunidad Autónoma y obviamente a la ley de Sostenibilidad y Estabilidad Presupuestaria.

El contenido del artículo 10.3 de la Carta Europea de la Autonomía Local, ratificada por España, refuerza la interpretación que se mantiene, al establecer: "Las Entidades locales pueden, en las condiciones eventualmente previstas por la Ley, cooperar con las Entidades de otros Estados” viene a apoyar la interpretación que se efectúa porque en virtud de este tratado las entidades locales están facultadas para cooperar, y la ley ha de establecer las condiciones, lo cual hace muy claramente el precepto transcrito (articulo 20 LCID).

“La Carta Europea de Salvaguarda de los Derechos Humanos en la Ciudad (2000), recoge la solidaridad como un derecho, y la cooperación municipal como una obligación,documento aprobado por más de 400 ciudades en toda Europa, Instituto de Derechos Humanos de Cataluña http://www.idhc.org/cat."

FONT MONCLUS et alter ${ }^{20}$

Alguna interpretación intermedia, entiende que, los servicios obligatorios del articulo 26 LRBRL son ya competencias propias para cada tramo de población y que, se pueden considerar también propias, las competencias atribuidas por norma con rango de ley por el Estado o la Comunidad Autónoma, sobre las materias contenidas o no en el artículo 25.2 actual siempre que esta atribución sea concreta y clara. Es decir, no una atribución genérica o inconcreta. En este sentido la Cooperación Internacional para el Desarrollo municipal y autonómica, contiene no solo una atribución competencial clara sino que la ley delimita su ejercicio por los entes locales, mediante una regulación amplia en la LCID, que establece no solo que se puede realizar CID sino además su regulación, incluida la de la sostenibilidad, al decir autonomía presupuestaria.

“Mientras tanto (se clarifican las competencias) y el mientras tanto puede ser largo, hay que gestionar inteligentemente la contingencia y evitar o eludir en la medida de lo posible los problemas (o, al menos amortiguarlos), buscando interpretaciones coherentes, sistemáticas, razonables y con sentido común, que se integren en el sistema de régimen local vigente..." 21

En cualquier caso si aún pese a lo anterior hubiera de algún modo que pronunciarse sobre la inexistencia de duplicidad o cualquier otra cuestión, se estima que el Ministerio de Asuntos exteriores y Cooperación (en adelante MAE) no debería tener ninguna dificultad en dictar una disposición general que declarara esta circunstancias respecto todas las entidades locales, porque desde luego la duplicidad, también es conforme figura en la norma un concepto jurídico indeterminado quizás podría predicarse o aparecer la duplicidad en cuanto a actuar en un concreto territorio, en un concreto proyecto que colisionara con otro en ejecución o planificado por otros actores, pero las necesidades en el ámbito de la cooperación para el desarrollo son tan amplias que no hay duplicidad. En cualquier caso, esta puede ser una muy buena ocasión para profundizar en la coordinación de las acciones de cooperación internacional para el Desarrollo que se lleven a cabo por las Comunidades Autónomas y los entes locales. Este es un camino ya iniciado o intentado por algunas experiencias como el Programa Municipia y que sería muy fácil retomar.

"A modo de conclusión, y por todo lo expuesto, no se considera aplicable el artículo 7.4 de la LRBRL que se solicita para el desenvolvimiento de la cooperación Internacional para el Desarrollo

19 FONT MONCLUS ET ALTER 2014, 19.

20 FONT MONCLUS ET ALTE 2014, 20.

21 JIMENEZ ASENSIO, 2015. 
por parte de las entidades locales; siendo, necesario, por el contrario, la comunicación previa de las actuaciones que se pretendan realizar a los órganos autonómicos y estatales con funciones de coordinación sobre la acción exterior, para así propender al aseguramiento de que sean conformes a los principios, fines, objetivos y áreas priorizadas en la planificación".

DGAL Junta Andalucía ${ }^{22}$

Por lo tanto y como conclusión hay que señalar:

a) Que la Ley 27/2013 LRSAL no ha afectado a la competencia ni al ejercicio de la Cooperación Internacional para el Desarrollo de los municipios y demás entes locales y por tanto que es una actividad que puede ser ejercida actualmente conforme a lo establecido en el artículo 20 de LCID y leyes autonómicas respectivas.

b) Que se trata de una competencia propia que además de atribuida por el legislador estatal, en el artículo 20 de la LCID, ha sido reconocido el interés local en este precepto, al conceptuarla "como expresión solidaria de sus sociedades" y al hacerlo así ha reconocido la existencia de un interés propio en Cooperación Internacional para el Desarrollo tanto de las CCAA como de los entes locales.

c) Que consecuentemente y conforme al artículo 2 de la Ley 7/1985 de 2 de abril RBRL, al reconocer ese interés propio y tratarse de un asunto que afecta directamente al círculo de sus intereses (la sociedad local) los municipios y demás entes locales tienen derecho a intervenir en esta materia y por tanto a ostentar competencias en ella.

d) Otra cosa es el alcance de estas competencias, que obviamente se ejercerán con autonomía presupuestaria y autorresponsabilidad debiendo respectar las directrices básicas y líneas generales establecidas por el Congreso de los Diputados, la colaboración con otras entidades y el máximo respecto a los recursos públicos e inspirándose en los principios objetivos prioridades establecidas en la sección 2. a del capítulo I de la presente Ley.

e) Para concluir, se trata de una competencia no obligatoria, cuyo ejercicio, al igual que el resto de competencias municipales se somete a la Ley Orgánica de Estabilidad y Sostenibilidad Presupuestaria.

“La Ley (27/2013) sigue plenamente vigente, demostrando sus inefectividades que para las grandes reformas es preferible el consenso a la unilateralidad. Que cuando no se plantean en términos positivos, sino bajo la presión de una extrema urgencia, no persisten en el tiempo. Que en España los municipios son anteriores al Estado, A las Comunidades Autónomas y a las Diputaciones provinciales. Que la autonomía es fuerte y resistente por sus bases democráticas. Que no es nada fácil "racionalizar" la Administración Local."

\section{Ribero Ortega ${ }^{23}$}

No obstante lo anterior, el abogado del Estado del MAEC ha emitido un informe, en 10 de diciembre de 2014, que ha sido ratificado por el abogado general, que concluye:

"El nuevo modelo competencial de las entidades locales definido por la Ley 27/2013, de 27 de diciembre, de Racionalización y Sostenibilidad de la Administración Local, determina que, con arreglo a lo dispuesto en el artículo 7.4 de la Ley 7/1985 de 2 de abril, reguladora de las Bases de Régimen Local, las entidades locales que, al margen de la técnica de delegación de competencias prevista en el artículo 27 de dicha norma pretendan realizar actividades de cooperación internacional para el desarrollo y que no tengan delegada esa competencia, deban solicitar informe previo y vinculante del Ministerio de Asuntos Exteriores y de Cooperación y de la respectiva Administración de la Comunidad Autónoma cuando ésta haya asumido competencias en esta materia, en el que se señale la inexistencia de duplicidades.

Asimismo, deberán solicitar de la Administración que tenga atribuida la tutela financiera informe previo y vinculante sobre la sostenibilidad financiera de la competencia. En el caso de las Comunidades Autónomas de Andalucía, Aragón, Principado de Asturias, Castilla y León, Cataluña, Galicia, Navarra, País Vasco, La Rioja y Comunidad Valenciana, la elaboración del referido informe corresponderá a la

22 DIRECCION GENERAL ADMINISTRACION LOCAL JUNTA DE ANDALUCIA, 2014

23 RIVERO ORTEGA, 2015, 8. 
Consejería que tenga atribuidas las competencias en materia de tutela financiera sobre las Entidades Locales, mientras que, en los restantes supuestos corresponderá al Ministerio de Hacienda y Administraciones Públicas ${ }^{24}$."

\section{LAS COMPETENCIAS EN COOPERACION INTERNACIONAL PARA EL DESARROLLO Y LA LEY 2/2014, DE 25 DE MARZO DE LA ACCIÓN Y DEL SERVICIO EXTERIOR DEL ESTADO. CUESTIONES PUNTUALES.}

La Ley 27/2013 LRSAL, vino a poner en duda para algunos, la facultad de los entes locales para ejercer competencias en Cooperación Internacional para el Desarrollo, cuestión que en estos momentos está resuelta para gran parte de los entes locales, ya que se estima que subsisten las normas sectoriales que atribuyeron competencias con anterioridad a la entrada en vigor de la LRSAL. Así como el artículo 20 de la Ley 23/1989 de Cooperación Internacional para el Desarrollo en adelante LCID, atribuyó esta competencia a los entes locales, esta subsiste actualmente al no haber sido derogado aquél precepto ${ }^{25}$.

Las CCAA también tienen competencia en la materia, derivado en muchos casos de su Estatuto de Autonomía y de sus respectivas leyes y en cualquier caso del mismo artículo que la atribuye a los entes locales.

Recientemente la ley 2/2014, de 25 de marzo de la Acción y del servicio exterior del Estado (en adelante LASEE), ha venido a reafirmar la competencia de los entes locales y Comunidades Autónomas desde un ámbito más amplio: la acción exterior. Esta Ley es aplicable a la Cooperación Internacional para el Desarrollo, porque la Cooperación Internacional para el Desarrollo (en adelante CID) es acción exterior, aunque no toda la acción exterior es cooperación internacional para el desarrollo. La CID es una parte que además contiene especialidades que habrá que integrar en la acción exterior.

“En cambio, el texto (de la Ley) ... confiere una relevancia indudable en el marco de la acción exterior a la cooperación internacional al desarrollo, cuyo entronque con nuestra venerable Constitución —cuyo Preámbulo impone el desarrollo de unas 'relaciones de eficaz cooperación con todos los pueblos de la tierra'- reconoce E incluso este compromiso parece verse reforzado en sus disposiciones pues ya en el art. 2.d) enuncia como uno de los objetivos de la política exterior de España "la lucha contra la pobreza, la solidaridad con los países en vías de desarrollo y el desarrollo económico y social de todos los Estados."

\section{GONZALEZ VEGA 26}

Conforme al artículo 2.2 de la LASEE: Son objetivos de la política exterior de España: d) La lucha contra la pobreza, la solidaridad con los países en vías de desarrollo y el desarrollo económico y social de todos los Estados. Con este precepto bastaría para integrar la CID en el ámbito de la Ley, aunque hay referencias todavía mas concretas.

Las siguientes líneas contienen algunas opiniones de urgencia sobre cuestiones puntuales de la LASEE en relación con la CID.

El artículo 3 de la LCID sitúa a la política de cooperación internacional para el desarrollo como parte de la acción exterior del Estado y se basa en el principio de unidad de acción del Estado en el exterior. La ley de Acción y del servicio exterior del Estado, señala en su artículo 1 que su objeto es regular la Acción Exterior del Estado, enumerar sus principios rectores, identificar los sujetos y ámbitos de la misma, establecer los instrumentos para su planificación, seguimiento y coordinación y ordenar el Servicio Exterior del Estado, para asegurar la coordinación y coherencia del conjunto de actuaciones que la constituyen y su adecuación a las directrices, fines y objetivos de la Política Exterior. Se define la acción exterior artículo 1.2.b de la LASEE (en la que como se ha dicho el artículo 3 de la LCID enmarca la Cooperación para el desarrollo) como el conjunto ordenado de las actuaciones que los órganos constitucionales, las Administraciones públicas y los organismos, entidades e instituciones de ellas dependientes llevan a cabo en el exterior, en el ejercicio de sus respectivas competencias, desarrolladas de acuerdo con los principios establecidos en esta ley y con observancia y adecuación a las directrices, fines y objetivos establecidos por el Gobierno en el ejercicio de su competencia de dirección de la Política Exterior. Sin duda las entidades locales y las Comunidades Autónomas (en adelante CCAA) son administraciones públicas por lo que esta ley les es de

24 Conclusiones a las que se llega, a partir de razonamientos fundados en el Dictamen Inicial del Consejo de Estado al proyecto de Ley y que ha sido superado. El informe del abogado del Estado puede verse integro en ver en http://www.femp.es/files/3580-995-fichero/ Dictamen\%20de\%2ola\%20Abogac\%C3\%ADa\%20General\%20del\%20Estado.pdf.

25 No obstante lo anterior.

26 GONZALEZ VEGA, JAVIER A. 2014. 
aplicación, y no solo genéricamente sino como veremos seguidamente refiriéndose a ellas. Además la LASEE regula en el capítulo II del Título I que denomina “Ámbitos de la Acción Exterior del Estado”, donde incluye entre otros la Cooperación Internacional para el Desarrollo (artículo 24), En el artículo 14, de la misma ley, se establece que a través de los instrumentos de planificación previsto en la ley (artículo 34), le corresponde velar porque la acción exterior se dirija a lo que se considere prioritario para la política exterior, pudiendo instar la actuación de los órganos, sujetos y actores para la consecución de esos fines. Se prevé aquí la participación de las CCAA pero no de los entes locales. En base a este precepto y en concordancia con el artículo 97 de la Constitución Española de 1978, se reconoce que el Gobierno dirige la política exterior. Es más, de una lectura inicial parece desprenderse que no sólo se subordina la actuación de las CCAA a los fines de política exterior del Estado, sino que además se le puede "instar", es decir requerir para que actúen para el cumplimiento, extremo que hay que entender en el sentido de que cuando actúen en acción exterior habrán de hacerlo conforme a los fines de la política exterior. Fines objetivos y que figuran en la Ley.

\subsection{La planificación de la acción exterior, incluida la Cooperación Internacional para el Desarrollo. (Título II de la LASEE)}

Se declara por la LASEE que la Acción Exterior del Estado, como elemento esencial para la ejecución de la Política Exterior, se desarrollará en el marco de los instrumentos de planificación regulados en esta ley, y se sujetará a los principios, directrices, fines y objetivos de dicha política (artículo 3.1 LASEE). Esta referencia por lo que afecta a la CID, debe considerarse que se refiere además de a la planificación contenida en la misma, a la que como se ha dicho se ha de someter la CID de las entidades locales y las Comunidades Autónomas, conforme a las remisiones que efectúa el artículo 20 LCID. Subsisten los Planes Directores de Cooperación, tanto del Estado como de las CCAA.

La planificación se regula en el artículo 34 y siguientes de la LASEE, que señala que la planificación y el seguimiento de la acción exterior (toda), se llevará a cabo a través de la Estrategia de Acción Exterior y el Informe de Acción Exterior (artículo 37 LASEE). El informe de acción exterior viene a suprimir el Plan Anual. En este sentido, la propia LASEE modifica la LCID para eliminar la referencia al plan anual de Cooperación de la misma.

En la elaboración tanto de la Estrategia como del informe de acción exterior, se prevé que actúen las administraciones públicas, es decir las CCAA y los entes locales (artículo 35 LASEE)

Por lo que se refiere a la Estrategia de acción exterior, se configura como una súper planificación que va a incluir todos los "ámbitos de la acción exterior del Estado", recogiendo todas las actuaciones, incluidas las de todas entidades públicas. La elaboración corresponde al MAE, e integrará propuestas de las CCAA y entidades locales. Corresponde su aprobación al Consejo de Ministros deberá ser previamente conocida y debatida en las Cortes Generales y su vigencia será de cuatro años.

En el informe Anual de Acción Exterior, se dará cuenta de la ejecución de la Estrategia, se elabora por el Gobierno y se prevé la participación de las CCAA y los entes locales entre otros. Se aprueba por el Consejo de Ministro y se publica en el B.O.E. (artículo 37 LASEE)

\subsection{Los sujetos de la acción exterior (artículo 5 LASEE)}

La ley hace numerosas referencias a los sujetos e incluye en la casi totalidad de sus previsiones a las CCAA y a las entidades que integran la Administración Local.

Además de las referencias a las Administraciones públicas en general entre las que sin duda se encuentran las CCAA y entidades locales, el artículo 5 señala que son sujetos de la Acción Exterior del Estado, los órganos constitucionales, las Administraciones públicas y los órganos administrativos, instituciones y entidades que, en el ejercicio de sus propias competencias, actúan y se proyectan en el exterior,

\subsection{Sobre la obligación de mantener informado o comunicar al MAE las actividades de Cooperación por las} entidades locales

El artículo 5.2 de la LASEE establece que los órganos constitucionales, las Comunidades Autónomas, las Ciudades Autónomas, las entidades que integran la Administración Local y los organismos, entidades e instituciones de ellas dependientes mantendrán informado al Ministerio de Asuntos Exteriores y de Cooperación de las propuestas sobre viajes, visitas, intercambios y actuaciones con proyección exterior, para que este departamento pueda informar y, en su caso, emitir recomendaciones motivadas sobre la adecuación de la propuesta de actuación a las directrices, fines y objetivos de la Política Exterior fijados por el Gobierno y los instrumentos de planificación establecidos por esta ley. A la luz de este precepto, y si todavía existiera alguna, no cabe duda que las CCAA y entidades locales pueden realizar actuaciones en el exterior, actuaciones entre las que está la Cooperación 
Internacional para el Desarrollo, sobre todo en cuanto que se adecúe a los requisitos exigidos por la LCID en el artículo 20, se inspire en los principios objetivos y prioridades establecidas en la sección 2. a del capítulo I de la LCID y se base en los principios de autonomía presupuestaria y autorresponsabilidad en su desarrollo y ejecución, se respeten las líneas generales y directrices básicas establecidas por el Congreso de los Diputados a que se refiere el artículo 15.1 de la citada Ley y el principio de colaboración entre Administraciones públicas en cuanto al acceso y participación de la información y máximo aprovechamiento de los recursos públicos y también a l lo establecido en la LASEE singularmente a la planificación prevista a través de la Estrategia que obviamente habrá de recoger la de los planes Directores de Cooperación.

Una cuestión que deberá aclararse es en que supuestos hay que informar al MAE, porque la redacción de la norma precisa de concreción al incluir un concepto jurídico indeterminado "mantendrán informado al Ministerio de Asuntos Exteriores y de Cooperación de las propuestas sobre viajes, visitas, intercambios y actuaciones con proyección exterior" Hay una obligación de información, pero no de toda la actividad exterior sino sólo de las acciones que se señalan cuando tengan "proyección exterior”.

Para la LASEE la Acción Exterior del Estado es el conjunto ordenado de las actuaciones que los órganos constitucionales, las Administraciones públicas y los organismos, entidades e instituciones de ellas dependientes llevan a cabo en el exterior, en el ejercicio de sus respectivas competencias, desarrolladas de acuerdo con los principios establecidos en esta ley y con observancia y adecuación a las directrices, fines y objetivos establecidos por el Gobierno en el ejercicio de su competencia de dirección de la Política Exterior.

En materia de Cooperación Internacional para el Desarrollo en algún foro se ha planteado a la vista del artículo 5.2 de la LASEE si debería informarse al Ministerio de todas las actuaciones, es decir de cada convocatoria de ayudas, de cada proyecto o Convenio que se apruebe o de cada proyecto que se vaya a ejecutar directa o indirectamente en el exterior por cualquier ente local, de cada viaje, visita, etc. Estimo que cualquiera que sea la forma de gestión de la Cooperación Internacional, a través de concesión de ayudas a actores de la cooperación o mediante acuerdos directos, convenios entre entes locales del Norte y del Sur, etc. no estamos en general ante actuaciones con proyección exterior. Son actuaciones en el exterior, pero "proyección" añade un plus que algunas actuaciones tendrán y otras no. Para la Real Academia de la Lengua proyección es en la cuarta de sus acepciones: "Resonancia o alcance de un hecho o de las cualidades de una persona". Lo que supone que para tener relevancia debe tratarse de una actuación que por su visibilidad, por la relevancia de las personas o instituciones que interviene, por la cuantía de su importe, por el momento histórico o país en que se produzca, etc. exceda de lo ordinario, de lo habitual. Nuevamente los juristas nos encontramos aquí ante conceptos jurídicos indeterminados y para determinarlos, será necesario examinar cada supuesto. Sin embargo no es aventurado mantener ya que, cuando las actuaciones que se realicen o pretendan realizar se enmarquen dentro de la Estrategia de Acción Exterior y la planificación autonómica y/o Estatal, (Planes Directores) y cumplan con los requerimientos del artículo 20 LCID y de esta ley no será necesaria la comunicación. Tampoco lo seria cuando se trate de viajes o visitas ordinarias efectuadas por responsables políticos o funcionarios en el marco de la ejecución de sus políticas de Cooperación, sea directa o indirecta, siempre que se trate de políticas integradas o previstas en la Estrategia de Acción Exterior. Solo cuando se trate de viajes o visitas, en el marco de la Cooperación, que incluyan visitas y relaciones con alcaldes de grandes ciudades, gobernadores de entes subnacionales o con miembros del Gobierno de países del Sur, y estás adquieran una dimensión más allá del propio proyecto de cooperación estimo que procedería considerar que tienen proyección exterior. Del mismo modo la suscripción de convenios para la ejecución directa de proyectos de cooperación de cuantía muy elevada, de actuaciones en lugares o materias sensibles para la política exterior, etc. podría considerarse de relevancia. Quizás fuera deseable que el Ministerio aclarara esta cuestión, que entendemos que no pasa por comunicar cualquier actuación que se realice o pretenda realizar en el exterior. $Y$ todo ello sin perjuicio de que la necesaria coordinación de acciones de Cooperación para el incremento de su eficacia precise de mecanismos de información recíproca. Para su incorporación al informe anual de acción exterior, si estimamos que será obligatoria la comunicación.

En cualquier caso, si no se aclara por el Ministerio, mediante la oportuna disposición, las CCAA podrían elaborar un documento donde señalar que entienden por proyección exterior y además regular la forma de comunicación.

El artículo 11 de la LASEE por su parte señala que las actividades que las Comunidades Autónomas, las Ciudades Autónomas y las entidades que integran la Administración Local puedan realizar en el exterior en el marco de las competencias que les sean atribuidas por la Constitución, por los Estatutos de Autonomía y las leyes, respetarán los principios que se establecen en esta ley y se adecuarán a las directrices, fines y objetivos de la Política Exterior fijados por el Gobierno. Este precepto en cuanto a la Cooperación internacional viene a reiterar el contenido del artículo 20 de la LCID, ahora referido a la LASEE. 
Asimismo, dichas actividades de las Comunidades y Ciudades Autónomas se adecuarán a los instrumentos de planificación de la Acción Exterior, elaborados y aprobados de conformidad con lo dispuesto en esta ley y establecidos por el Estado en el ejercicio de sus facultades de coordinación en este ámbito, cuando definan directrices de actuación propias de la Política Exterior del Estado o se inserten en el ámbito de las relaciones internacionales de España.

\subsection{Las entidades que integran la Administración Local estarán sujetas a los instrumentos de planificación de la acción exterior que determinen sus respectivas Comunidades Autónomas}

Aunque no se dice expresamente se está declarando por el artículo 1 de la LASEE que la actuación de los entes locales está subordinada, sometida o regulada por la planificación de las Comunidades Autónomas y esta a su vez a la del Estado, lo que conduce, que en la Acción exterior y por tanto en Cooperación Internacional se prevé una planificación de arriba a abajo, los entes locales integran sus actuaciones y en su caso, su planificación en la de la CCAA y después estas a su vez en la del Estado. De este precepto deriva que las CCAA han de determinar, mediante la oportuna norma a que instrumentos de planificación de la acción exterior se han de subordinar los entes locales. Parecería que habrá de ser al plan director de Cooperación, aunque la norma parece ir más lejos y seria a la planificación de la acción exterior. De toda la acción de la que solo una parte es la Cooperación.

Las actuaciones que se lleven a cabo en el ejercicio de la Acción Exterior no podrán comportar, en ningún caso, la asunción de la representación del Estado en el exterior, la celebración de tratados internacionales con otros Estados u organizaciones internacionales, la generación, directa o indirecta, de obligaciones o responsabilidades internacionalmente exigibles al Estado, ni incidir o perjudicar la Política Exterior que dirige el Gobierno ${ }^{27}$. Corresponde en cualquier caso al Gobierno establecer las medidas y directrices que regulen y coordinen las actividades en el exterior de las Comunidades Autónomas y Ciudades Autónomas con el objeto de garantizar el cumplimiento de lo dispuesto en esta ley (artículo 11 LASEE)

Resulta de este precepto que, el Gobierno puede regular y coordinar las actividades en el exterior de las CCAA, para garantiza lo dispuesto en esta ley, dice. Es muy posible que la norma se haya extralimitado, porque si bien es cierto que lo que es política exterior en sentido estricto es competencia exclusiva del Estado, no esta tan claro que pueda regularse toda la acción exterior, sobre todo en la amplitud con que se dice en el precepto. Quizás directrices, entendido como grandes líneas o principios básicos podrían tener cabida, pero medidas, así en abstracto, parece excesivo.

Las Comunidades Autónomas, las Ciudades Autónomas y las entidades que integran la Administración Local podrán celebrar acuerdos internacionales administrativos en ejecución y concreción de un tratado internacional cuando así lo prevea el propio tratado, les atribuya potestad para ello y verse sobre materias de su competencia. Asimismo, podrán celebrar acuerdos no normativos con los órganos análogos de otros sujetos de derecho internacional, no vinculantes jurídicamente para quienes los suscriben, sobre materias de su competencia (artículo 11.4 LASEE).

El Ministerio de Asuntos Exteriores y de Cooperación informará con carácter previo y de acuerdo con lo que disponga la legislación estatal que regule su celebración, los acuerdos internacionales administrativos y los no normativos que estas Administraciones pretendan celebrar con autoridades u órganos administrativos de un sujeto de derecho internacional. A tal efecto recabará el informe de los departamentos ministeriales competentes por razón de la materia (artículo 11.4).

No es muy comprensible jurídicamente hablar de acuerdos no normativos, y menos aún no vinculantes. Lo de no normativos puede hacer referencia a que son actos singulares, por contraposición a los generales, pero no se entiende lo de no vinculante. Porque por definición un acuerdo supone poner en común dos voluntades para algo y un compromiso de ejecutar ese algo y unas consecuencias y mucho menos es comprensible que se haya de informar previamente por el Ministerio algo que no es vinculante ni genera compromisos. Una interpretación amplia de lo que haya que entender por acuerdo no vinculante jurídicamente debe conducirnos (en virtud de la ubicación de esta obligación) a que la no vinculación jurídica viene referida a que no puedan establecerse obligaciones o responsabilidades del Estado o que lo comprometan. Es decir que se trate de acuerdos entre administraciones, pero que no vinculen al Estado, en los términos que establece el propio precepto. Y el informe del Ministerio vendría referido precisamente a evitar que puedan derivarse esas responsabilidades para él, En este sentido, quizás podrían considerarse aquí incluidos los acuerdos o convenios entre administraciones una española y otra del Sur para la ejecución de proyectos de cooperación, que precisaría de informe del Ministerio, aunque tal y como se ha dicho más arriba, cuando estos convenios o acuerdos lo sean con el cumplimiento de los

27 Se recoge por la ley la reiterada jurisprudencia sobre ello. 
requerimientos del artículo 20 de la LCID y previstos singular o globalmente en la Estrategia, no se precisaría del informe. Necesitaremos también de una aclaración por parte del MAE.

\subsection{Las administraciones locales y las CCAA, tienen facultades para actuar en el exterior y por tanto en la Cooperación Internacional para el Desarrollo}

Todas estas referencias a la Administración Local y CCAA vienen a confirmar las facultades de las CCAA, los municipios y demás entes locales para actuar en el exterior y por tanto en el campo de la Cooperación Internacional para el Desarrollo que es parte de esta. La referencia al informe del Ministerio de AAEE y Cooperación, puede afectar a la Cooperación Directa es decir la que realizan las CCAA y los entes locales teniendo como contraparte a otra administración. Es decir ahora los convenios, acuerdos, protocolos, etc. que se suscriban entre los entes locales y las autoridades de otros Estados, por ejemplo, entre dos municipios uno español y otro de un país en desarrollo, deberán ser informados previamente por el Ministerio, siempre y cuando se aparten o no estén concretados en la planificación.

Estimo que no se precisa el informe cuando ello se lleve a cabo por una ONGD o cualquier otro actor de la Cooperación, para la ejecución de un proyecto de cooperación, aunque sea con fondos de administraciones públicas para esta finalidad. Las Ongds pueden suscribir convenios y compromisos con otras Administraciones en el Exterior, como sujetos de derecho privado que son y no están sometidos directamente a estas normas, sino a las que vinculan a cualquier otro particular que actúe en el exterior.

El Artículo 24 de la LASEE, señala que la Acción Exterior en materia de cooperación para el desarrollo se orientará a contribuir a la erradicación de la pobreza, al desarrollo humano sostenible y al pleno ejercicio de los derechos, mediante la consolidación de los procesos democráticos y el Estado de Derecho, la reducción de las desigualdades, el fomento de los sistemas de cohesión social, la promoción de los derechos de las mujeres y la igualdad de género; dando una respuesta de calidad a las crisis humanitarias.

El artículo 35.3 de la ley de acción exterior señala que el Ministerio de Asuntos Exteriores y de Cooperación recabará e integrará, en su caso, las propuestas de actuación exterior de los órganos constitucionales, de las Comunidades y Ciudades Autónomas y de las Entidades Locales. La no integración de las propuestas de los órganos y entes mencionados en el párrafo anterior deberá ser motivada y fundarse en la adecuación a las directrices, fines y objetivos de la Política Exterior fijados por el Gobierno.

Nuevamente nos encontramos ante un precepto confuso. Por una parte, porque el precepto dice que recabará e integrará " quiere decir que integrará las que recabe?” o bien que habrá una iniciativa para remitir y una obligación de integrar.

La Disposición final primera modifica varios preceptos de la Ley 23/1998, de 7 de julio, de Cooperación Internacional para el Desarrollo LCID, para adaptarla al contenido de la Ley de acción exterior. Esta modificación posterior a la LRSAL y que afecta a varios artículos deja vigente en su totalidad el artículo 20 de la LCID que es en el que se fundamenta conforme se ha reiterado más arriba la competencia de los entes locales en materia de cooperación internacional para el Desarrollo. Así pues si no fuera suficiente con todos los argumentos señalados, esta Ley viene a ratificar y fortalecer los argumentos dados de que la CID es una competencia directa de los entes locales.

\section{INSTITUCIONALIZAR A LA COOPERACIÓN INTERNACIONAL DE LOS ENTES LOCALES}

Las entidades locales acometieron la Cooperación Internacional al Desarrollo como una respuesta a las demandas ciudadanas y la mayoría lo hicieron con más voluntad que recursos. El resultado ha sido desigual. Actualmente comparten el escenario entidades locales que han diseñado sus propios planes de Cooperación y los han ejecutado con resultados notables y otras muchas, que no lo han hecho demasiado bien y lo que es peor algunas que lo han hecho sin tener en cuenta que la Cooperación es acción exterior y por tanto parte de la política exterior del Estado.

En estos momentos, las normas examinadas permiten una mayor coordinación de las actuaciones de los entes locales, excesivamente dispersas, coordinación que habrá de respetarse. La LASEE y la propia literalidad del artículo 20 de la LCID unido a la disposición adicional primera del Real Decreto que desarrolla la disposición adicional 18. de la Ley General de Subvenciones, que establece que "Acuerdos con comunidades autónomas y entes locales.- En cumplimiento de la Declaración de París sobre la eficacia de la ayuda al desarrollo y de acuerdo con el mandato del artículo 20 de la Ley 23/1998, el Ministerio de Asuntos Exteriores y de Cooperación promoverá la formalización de acuerdos para el desarrollo de normativas convergentes con las comunidades autónomas y con los entes locales o con las asociaciones de estos, de ámbito estatal o autonómico, previstas en las disposiciones 
adicionales quinta y decimotercera de la ley $7 / 1985$, de 2 de abril, de Bases de Régimen Local, en el marco de sus respectivas competencias y de acuerdo con lo establecido en la Ley 38/2003, de 17 de noviembre, General de Subvenciones, su Reglamento general de desarrollo y este real decreto")

Estimo que, la planificación establecida por la Ley 2/2014, de 25 de marzo, de la Acción y del Servicio Exterior del Estado a través de la Estrategia, junto con los planes Directores previstos tanto en la LCID como en la mayor parte de Comunidades Autónomas así como las previsiones del articulo 20 LCID que somete la actuación de los entes locales a los principios y directrices del Estado y la disposición adicional citada, podrían dar lugar a que la CID de las entidades locales, se coordinara mejor a nivel Estatal mediante un acuerdo entre estas, e incluso mediante una norma. Todo ello debería confluir en el Plan Director de Cooperación Estatal y este en la Estrategia. Se trataría de una planificación de los entes locales, que se integrarían en la de la Comunidad Autónoma y a su vez ésta en la del Estado y también mediante la participación de todos los actores en la planificación Estatal.

Con ello y sin perjuicio de que la CID desde las entidades locales sea una actividad voluntaria y sometida a todas las consideraciones que se quiera, se conseguiría la configuración definitiva de lo que siempre ha estado claro, que las actuaciones en el exterior, cuanto menos deben estar coordinadas internamente, entre todos los poderes públicos que actúen en ese ámbito y a la vez su institucionalización en lo local de modo que se sientan empoderadas, que de una vez por todas, se asuma no solo externamente, sino también internamente por las propias entidades locales que la Cooperación es tarea propia, con un sentido que va más allá de ser una competencia propia, como es.

La planificación de las Comunidades Autónomas tanto de la CID como de la Acción exterior además de contener las actividades de los entes locales para a su vez integrarla en la del Gobierno, para construir la del Estado, debería prestar especial atención a la suma de esfuerzos de los entes locales entre sí y aprovechar sus capacidades y experiencias.

La cooperación internacional para el desarrollo de los entes locales, la de las CCAA y las del Estado que persiguen los mismos objetivos, han de hacerse de modo integrado y coordinado. La planificación es un buen instrumento y no ha de suponer sumisión alguna de unos actores respecto a otros. La ley LASEE pone sobre la mesa un nuevo instrumento de planificación en el que integrar la de la CID.

Es el momento de plantearse como debemos hacerlo desde los municipios y demás entes locales. El MAE tanto con el desarrollo reglamentario de la LASEE como en sus experiencias tiene mucho que decir, los entes locales deberían propiciar e iniciar una seria reflexión acerca de si es posible y conveniente y sobre todo eficaz, seguir actuando como hasta ahora o comenzar a sumar a través de la integración en los planes directores y en la estrategia de la acción exterior general.

Obviamente la normativa que se dicte o los programas que puedan establecerse para llegar a normativas convergentes no deben suponer en ningún caso subordinación de la cooperación internacional para el Desarrollo de los entes locales a la de las Comunidades Autónomas ni a la del Estado, el propio precepto habla de acuerdos. Los entes locales pueden y deben diseñar sus propias políticas de Cooperación, al igual que las CCAA. La integración en la Estatal es posible sin subordinar una a otra, porque, sin necesidad de ello, pueden complementarse y sumarse unas a otras, para el logro del principal objetivo de la Cooperación: La erradicación de la pobreza.

\section{ABREVIATURAS}

LRSAL: ley 27/2013, de 27 de diciembre, de racionalización y sostenibilidad de la Administración Local. LRBRL: Ley $7 / 1985$, de 2 de abril Reguladora de las Bases del Régimen Local.

LCID: Ley 23/1998, de 7 de julio de Cooperación Internacional para el desarrollo.

LASEE: Ley 2/2014, de 25 de marzo, de la acción y del servicio exterior del Estado.

CID: Cooperación Internacional para el Desarrollo.

MAEC: Ministerio de Asuntos Exteriores y de Cooperación.

\section{BIBLIOGRAFIA}

ARENILLA SAEZ, MANUEL, Catedrático de Ciencia Politica y de la Administración, Universidad Rey Juan Carlos. Director del INAP, Revista de Estudios de Administración Local y Autonómica, n. ${ }^{\circ}$ extraordinario enero 2015.

BELLO PAREDES, SANTIAGO A., profesor de Derecho Administrativo. Universidad de Burgos. Presentación. Revista de Estudios de Administración Local, REALA. Núm. Extraordinario, enero $2015 a$. 
BELLO PAREDES, SANTIAGO A., profesor de Derecho Administrativo. Universidad de Burgos. Las competencias locales: balance de situación. Revista de Estudios de Administración Local, REALA. Núm. Extraordinario, enero 2015b.

CASES I PALLARÉS, JORDI, Secretario del Ayuntamiento de Barcelona Revista de Estudios Locales, CUNAL, n. ${ }^{\circ} 169,2014$.

COSITAL, CR., Aproximación al nuevo marco competencial y organizativo de los pequeños y medianos Ayuntamientos y de las Diputaciones tras la ley 27/2013. Colegio Provincial de Secretarios Interventores y Tesoreros de la Administración Local de Ciudad Real, 2013. http://www.cositalcr.es/Ficheros/ documentos/20140317_Aproximacion\%20al \%20nuevo\%20marco\%20competencial\%20de\%20 ayuntamientos\%20y\%20diputaciones.pdf.

DE DIEGO GOMEZ, ALEJANDRO, http://laadministracionaldia.inap.es 4/07/2014.

FONT MONCLUS, JOAN ANTON, Secretario General del Ayuntamiento de Tarragona.

GUTIERRES BUSTILLO,JESUS, Secretario General del Ayuntamiento de Leyda.

SAGALES GUILLAMON, JOAN RAMON, Interventor General del Ayuntamiento de Cornellà de Llobregat. http:// www.fonscatala.org/upload/archivos//20150108_0636Informe_LRSAL-Cooperacio_Cast.pdf.

Dictamen jurídico emitido por COSITAL de Catalunya sobre la competencia de los municipios en materia de Cooperación Internacional, en el marco de aplicación de la LRSAL y sobre la Justificación de las aportaciones económicas que los Ayuntamiento tramitan a través del Fons Català de Cooperació al Desenvolupament, 2014 .

DIRECCION GENERAL DE ADMINISTRACION LOCAL DE LA CONSEJERIA DE ADMINISTRACION LOCAL DE Y RELACIONES INSTITUCIONALES DE LA JUNTA DE ANDALUCIA. (DGAL JA) Informe de de 31 de marzo de 2014 (pone de 2004).

GONZÁLEZ VEGA, JAVIER A., Catedrático de Derecho Internacional público y Relaciones Internacionales de la Universidad de Oviedo. Revista de Educación, Cooperación y Bienestar Social. Sobre el futuro de la Cooperación al Desarrollo a la luz de la nueva Ley de Acción Exterior. Núm 4 junio 2014 pp 75-80.

GRUPO DE TRABAJO DE TECNICOS DE COOPERACION federación Española De Municipios y provincias,manual de gestión de la cooperación para el desarrollo de los gobiernos locales, 2011. http://www.femp.es/files/5661077-archivo/ManualdeCooperaci\%C3\%B3nFEMP2011.pdf.

MARTIN PEREZ, PEDRO ANTONIO, La Cooperación Internacional al Desarrollo como competencia propia Municipal a la luz de la Ley 27/2013, de 27 de diciembre, de Racionalización y Sostenibilidad de la administración Local (B.O.E. de 30 de diciembre de 2013). El Blog de esPublico, http://administracionpublica. com/la-cooperacion-internacional/2014.

JIMENEZ ASENSIO, http//laadministracionaldia.inap.es, 23/12/2014.

RIVERO ORTEGA, RICARDO. Catedrático de Derecho Administrativo Universidad de Salamanca. "Oportunidades, riesgos y resultados reales de la Ley de racionalización y sostenibilidad de la Administración Local”. Revista de Estudios de Administración Local. REALA. Núm Extraordinario. Enero 2015.

SALAZAR BENITEZ, OCTAVIO. Universidad de Cordoba, en comunicación al XIII Congreso de la Asocación de Constitucionalistas de España. Comunicación Zaragoza, 2015. 
